\title{
LETTER
}

\section{The Relationship Between Sleep and Quality of Life in Type 1 Diabetes Patients}

Ellen M. S. Xerfan · Jane Tomimori · Rachel G. Albuquerque •

Sergio Tufik · Monica L. Andersen

Received: March 12, 2019 / Published online: April 26, 2019

(C) The Author(s) 2019

Keywords: Autoimmune diseases; Diabetes; Inflammation; Quality of life; Sleep; Sleep disorders

\section{Dear Editor,}

We read with interest the recent detailed and informative article titled "Quality of life is markedly impaired by rheumatological and skin manifestations in patients with type 1 diabetes: A questionnaire survey" [1]. We congratulate the authors on this important study that shows the extent to which the condition and its clinical outcomes can affect the quality of life of patients.

We are writing to highlight the links that have been established between the quality of life of individuals with other autoimmune diseases, including skin conditions such as vitiligo, and sleep and to suggest that this relationship

Enhanced Digital Features To view enhanced digital features for this article go to https://doi.org/10.6084/ m9.figshare.7982255

E. M. S. Xerfan · J. Tomimori

Department of Dermatology, Universidade Federal de São Paulo (UNIFESP), São Paulo, Brazil

R. G. Albuquerque · S. Tufik · M. L. Andersen ( $₫)$ Department of Psychobiology, Universidade Federal de São Paulo (UNIFESP), São Paulo, Brazil e-mail: ml.andersen12@gmail.com should be taken into consideration when studying T1DM.

It is known that there is a bidirectional relationship between sleep and inflammation. It is also known that persistent inflammation is associated with diseases such as metabolic syndrome, cardiovascular disease, some types of neoplasia and type 2 diabetes [2, 3]. Glucose metabolism, insulin sensitivity and metabolic syndrome are modulated by sleep loss, which leads to sleep disorders and poor sleep quality $[3,4]$. However, it remains unclear how the complex mechanisms of the sleep process could be specifically affected by T1DM. There is some evidence of a link between glucose levels in T1DM and sleep quality but this has not as yet been fully elucidated.

A study with 48 T1DM patients [5] measured sleep quality using the Pittsburgh Sleep Quality Index (PSQI) questionnaire, and poor sleep quality was reported by $46 \%$ of patients. Similarly, a systematic review and meta-analysis studies using validated questionnaires have shown that T1DM patients with lower HbA1c levels reported good sleep quality, while patients with poor sleep quality have higher HbA1c levels [6].

We believe, therefore, that in future studies it is important to consider the role of sleep. We suggest that in addition to using a questionnaire about quality of life, a specific questionnaire about sleep should also be included. 
Although polysomnography is considered the gold standard for evaluating sleep disorders, sleep questionnaires would be relatively easy to apply alongside quality of life measures and could provide important data.

In conclusion, there is currently a great deal of scientific interest in autoimmune diseases and their association with the complex mechanisms of sleep, but it is important to build a better understanding of this relationship, including in T1DM patients. We suggest that this be considered in future, with the aim of improving sleep quality in these individuals and, consequently, their quality of life.

\section{ACKNOWLEDGEMENTS}

Funding. This study was supported by Associação Fundo de Incentivo à Pesquisa (AFIP). R.G.A. received the Sao Paulo Research Foundation (FAPESP) Fellowship (\#2014/ 27329-5). S.T. and M.L.A. received CNPq fellowships. No funding or sponsorship was received for the publication of this article.

Authorship. All named authors meet the International Committee of Medical Journal Editors (ICMJE) criteria for authorship for this article, take responsibility for the integrity of the work as a whole, and have given their approval for this version to be published.

Disclosures. The authors, Ellen M.S. Xerfan, MD; Jane Tomimori, MD PhD; Rachel G. Albuquerque, PhD; Sergio Tufik, MD PhD; and Monica L. Andersen, PhD, have nothing to disclose.

Compliance with Ethics Guidelines. This article is a commentary piece and so does not contain any patient research or studies with human participants or animals performed by any of the authors.

Open Access. This article is distributed under the terms of the Creative Commons Attribution-NonCommercial 4.0 International License (http://creativecommons.org/licenses/ by-nc/4.0/), which permits any noncommercial use, distribution, and reproduction in any medium, provided you give appropriate credit to the original author(s) and the source, provide a link to the Creative Commons license, and indicate if changes were made.

\section{REFERENCES}

1. Nørgaard K, Kielgast U. Quality of life is markedly impaired by rheumatological and skin manifestations in patients with type 1 diabetes: a questionnaire survey. Diabetes Ther. 2019;10:635-47.

2. Zielinski MR, Krueger JM. Sleep and innate immunity. Front Biosci (Schol Ed). 2011;3:632-42.

3. Tufik SB, Berro LF, Andersen ML, et al. Prevalence and classification of sleep-disordered breathing. Lancet Respir Med. 2015;3:263-4.

4. Martins RC, Andersen ML, Tufik S. The reciprocal interaction between sleep and type 2 diabetes mellitus: facts and perspectives. Braz J Med Biol Res. 2008;41:180-7.

5. Martyn-Nemeth P, Phillips SA, Mihailescu D, et al. Poor sleep quality is associated with nocturnal glycaemic variability and fear of hypoglycaemia in adults with type 1 diabetes. J Adv Nurs. 2018;74:2373-80.

6. Reutrakul S, Thakkinstian A, Anothaisintawee T, et al. Sleep characteristics in type 1 diabetes and associations with glycemic control: systematic review and meta-analysis. Sleep Med. 2016;23:26-45. 